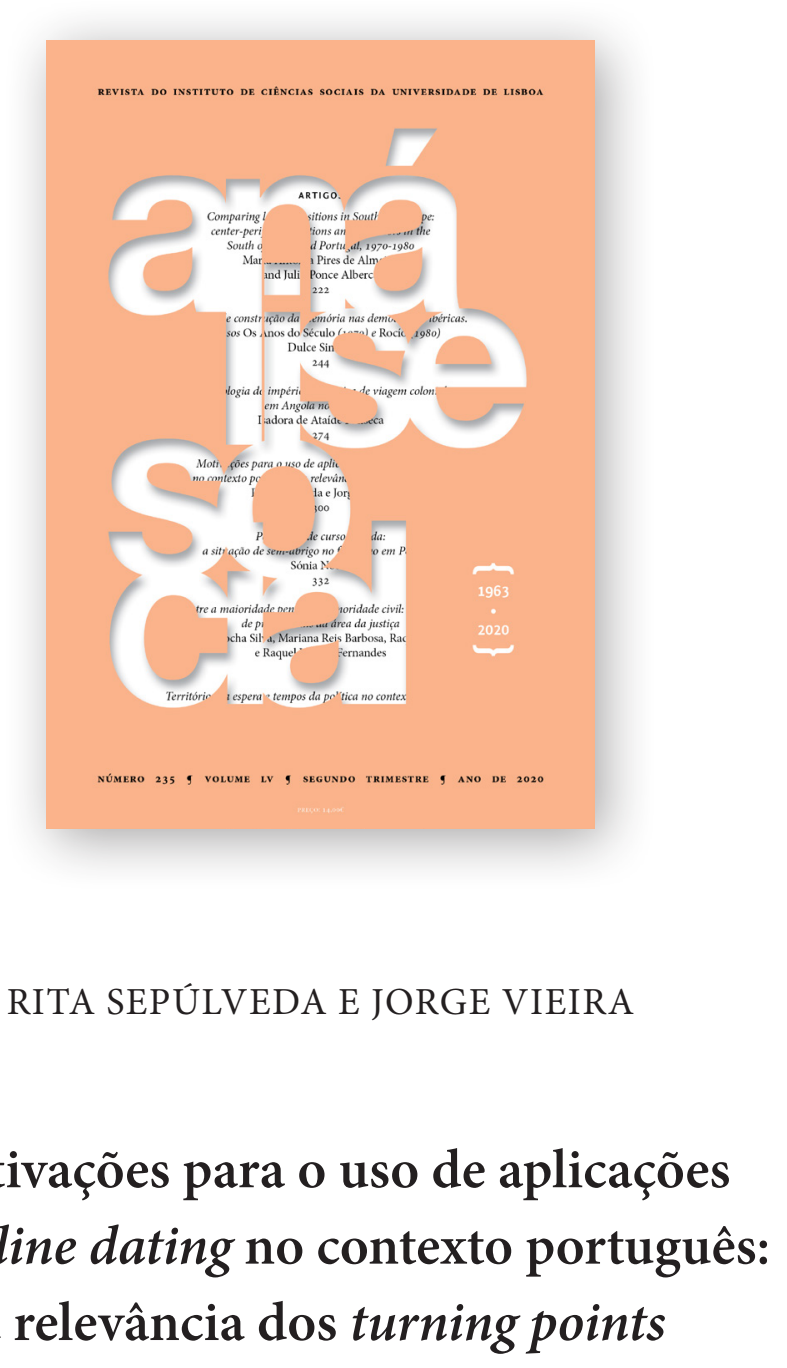

\title{
Motivações para o uso de aplicações de online dating no contexto português: a relevância dos turning points
}

Análise Social, LV (2. $\left.{ }^{\circ}\right), 2020$ (n. $\left.{ }^{\circ} 235\right)$, pp. 300-330 https://doi.org/10.31447/ASO0032573.2020235.04 ISSN ONLINE 2182-2999 
Análise Social, 235, LV $\left(2 .^{\circ}\right), 2020,300-330$

Motivações para o uso de aplicações de online dating no contexto português: a relevância dos turning points. Este artigo pretende contribuir para a discussão dos usos de soluções de online dating, concretamente na contextualização das motivações que conduzem a essa prática, focando-se nos turning points ao longo das trajetórias de vida dos utilizadores. Para tal, recorreu-se a uma metodologia qualitativa, realizando-se entrevistas semiestruturadas a 27 utilizadores portugueses da aplicação Tinder. Através da mesma, a presente investigação fornece dados respeitantes às motivações e à sua contextualização. Entre elas contam-se: socializar, procurar um relacionamento ou alguém com quem ter sexo. Estas motivações são contextualizadas por um conjunto de eventos entre os quais: término de um relacionamento, mudança de local de residência ou acontecimentos no âmbito do círculo de amigos que catalisam o uso de soluções de online dating.

PALAVRAS-CHAVE: turning points; Tinder; motivações; online dating.

Online dating solutions and turning points motivations in Portugal. This article aims to contribute to the discussion on the use of online dating solutions, concretely in the context of the motivations that lead to this use, focusing on the turning points along users' life trajectories. A qualitative methodology was applied, and 27 semi structured interviews take place with Portuguese users of online dating app Tinder. The present research provides evidence regarding the contextualization of motivations. Among them are: socializing, looking for a relationship or someone to have sex with. These motivations are contextualized by a set of events including: ending a relationship, change of residence or events within the circle of friends that catalyze the use of online dating solutions.

KEYWORDS: turning points; Tinder; motivations; online dating.

https://doi.org/10.31447/ASO0032573.2020235.04 


\section{Motivações para o uso de aplicações de online dating no contexto português: a relevância dos turning points.}

\section{INTRODUÇÃO}

Atualmente, o recurso à internet está presente num conjunto de tarefas diárias, abarcando diversas dimensões da vida em sociedade (Finkel et al., 2012) entre as quais se incluem as plataformas para a procura de amor, relacionamentos ou sexo, agrupadas numa área específica dos media sociais: os serviços de online dating.

Nos últimos anos, os meios, formatos e dinâmicas neste contexto específico de online dating registaram um crescimento na oferta e na procura (Albury et al., 2017), bem como um processo de diversificação, acompanhando a (r)evolução tecnológica e a consequente adoção e incorporação das tecnologias pelos utilizadores. Este processo tem sido acompanhado por parte da academia em áreas multidisciplinares como a psicologia, sociologia ou ciências da comunicação, produzindo-se estudos específicos que incidem sobre temáticas diversas como a autoapresentação e a autenticidade (Casimiro, 2014; Ward, 2016; Duguay, 2016; Vieira e Sepúlveda, 2017), motivações para usar (Sumter, Vandenbosch e Ligtenberg, 2016; Timmermans e De Caluwé, 2017; Ranzini e Lutz, 2017), incorporação das tecnologias no conjunto de atividades quotidianas (Pulgar, 2019; Hobbs, Owen e Gerber, 2016; MacKee, 2016; Licoppe, Riviére e Morel, 2016) e experiências dos utilizadores (David e Cambre, 2016; Duguay, 2016; Timmermans e Courtois, 2018).

Entre o conjunto de soluções disponíveis no mercado, as aplicações móveis têm conhecido um crescimento e a aplicação Tinder e os seus utilizadores registaram especial atenção tanto por parte da imprensa (Sepúlveda e Vieira, 2019) como por parte da academia (Timmermans e De Caluwé, 2017; Ward, 2016; Duguay, 2016). 
Estes serviços têm como denominador comum, e particularidade, o facto de as dinâmicas comunicacionais se desenvolverem de forma mediada especificamente com o recurso a tecnologias de informação e comunicação. Atualmente, a internet e as diversas soluções de online dating, nomeadamente as portáteis, vêm ocupar um espaço próprio, somando-se a atores sociais como a família, os colegas de trabalho e os amigos, no desempenho de funções de intermediação na apresentação de outros e permitindo aos indivíduos não estarem somente sujeitos às suas redes sociais (Hobbs, Owen e Gerber, 2016).

Neste sentido, o reconhecimento das alterações introduzidas pelo uso de tais soluções, mas também os motivos e momentos em que ocorrem, são importantes na medida em que são indicadores de respostas individuais a alterações produzidas na sociedade tanto ao nível tecnológico como também ao nível cultural e relacional, já que a procura de parceiro e o desenvolvimento de uma relação ocupam uma parte central ao longo das fases de vida e estágios de desenvolvimento dos indivíduos (Erikson, 1963).

A literatura sugere que o recurso a aplicações de dating está subjacente a um conjunto de motivações (Gudelunas, 2012; Van de Wiele e Tong, 2014; Sumter, Vandenbosch e Ligtenberg, 2016; Timmermans e De Caluwé, 2017; Ranzini e Lutz, 2017) entre as quais se destacam: socialização, desenvolvimento de relacionamentos, entretenimento e sexo casual. Porém, na identificação das motivações para o uso das referidas aplicações, os estudos até agora têm mobilizado maioritariamente metodologias quantitativas, não consentindo uma devida exploração e contextualização das mesmas de acordo com as alterações ocorridas na vida dos utilizadores.

Assim sendo, uma compreensão mais global do conjunto de motivações que conduzem a esse uso beneficiará se as mesmas forem contextualizadas tendo em conta uma leitura do curso de vida dos utilizadores. Neste contexto, a identificação dos pontos de viragem (turning points), definidos como eventos ou períodos que alteram a dimensão da vida de um indivíduo, percurso ou significado (Tester, 2018), e que se traduzem em combinações de atributos pessoais ou situacionais (Nico, 2016), são essenciais na contextualização e consequente compreensão das motivações que conduziram à utilização da aplicação.

Esta investigação pretendeu contribuir para o corpo de trabalho existente na área do online dating, colmatando a lacuna identificada e centrando a sua investigação em Portugal - país recetivo à tecnologia, sendo considerado um early adopter de diferentes soluções (Ganito, 2016), mas onde os estudos sobre online dating são ainda diminutos. Reside aqui a importância e pertinência da temática deste estudo, sendo que o objetivo foi o de identificar os turning 
points que conduziram à instalação e uso da aplicação Tinder, bem como as motivações subjetivas a essa utilização e contextualizá-las tendo em conta a biografia dos utilizadores. Para tal, o presente artigo apresenta dados da investigação qualitativa realizada junto de 27 utilizadores portugueses da aplicação Tinder com recurso a entrevistas semiestruturadas.

A investigação baseou-se numa pergunta de partida, através da qual se procurou perceber quais foram os acontecimentos na vida dos utilizadores que, segundo os mesmos, conduziram ao uso do Tinder e as motivações subjacentes a esse uso.

\section{TECNOLOGIA: INTERNET, REDES SOCIAIS, APPS E ONLINE DATING}

Em Portugal, $75 \%$ da população utiliza a internet, sendo que $60 \%$ o faz fora de casa através de um dispositivo móvel (Eurostat, 2019). No que diz respeito aos media sociais, estes estão grandemente imiscuídos na sociedade, fazendo parte da realidade diária de milhares de portugueses, na medida em que 64\% da população é ativa numa rede social, à qual 55\% acede através de telemóvel (Kemp, 2018). Esta informação remete para a importância da mobilidade, sendo consequentemente um indicador do recurso às tecnologias digitais e às aplicações móveis.

As redes sociais online constituem assim uma instituição de mediação através da qual é possível, entre outras funções, conhecer quem nunca se viu pessoalmente, e no caso concreto da oferta específica de online dating, proporcionar aos indivíduos a oportunidade de procurarem parceiros para relacionamentos ou sexo remetendo para uma alteração na iniciação dos processos de intimidade. No caso concreto do online dating, cujos objetivos de uso são mais específicos quando comparados com as redes sociais online, é possível, com a criação de um perfil através do qual o utilizador se apresenta, selecionar outros utilizadores em função de parâmetros de procura que podem ser tão diversos como o género, idade, atributos físicos, rendimento, entre outros (Whitty e Carr 2006).

Não obstante, convém relembrar que a procura de parceiros com recurso à mediação das tecnologias de informação e comunicação não é algo exclusivo da atualidade (Ellison, Heino e Gibbs, 2006; Finkel et al. 2012; Casimiro, 2014; Timmermans e Courtois, 2018) alterando-se em função da tecnologia disponível. Dos anúncios de jornal ao vídeo dating, do teletexto às agências matrimoniais e dos sites de online dating às atuais aplicações, as soluções tecnológicas para encontrar um parceiro, têm vindo a acumular-se (Anzani, Di Sarno e Prunas, 2018) e a adaptar-se tanto através da oferta como da procura por serviços online. 
Tal integração poderá repercutir-se em alterações ao nível cultural e social, nomeadamente nos diferentes graus de aceitação destas soluções por parte da sociedade ou dos pares. De facto, alguns autores reportaram uma mitigação do estigma associado ao recurso ao online dating e aos seus utilizadores em alguns contextos (Hobbs, Owen e Gerber, 2016).

Com a popularização dos smartphones, a instauração das lojas App Store e Google Play conduziram a uma multiplicação da oferta de aplicações - softwares especificamente desenvolvidos para operarem nos referidos dispositivos. Estas soluções digitais móveis diferenciam-se dos sites (Schrock, 2015; Yeo, 2018; Ranzini e Lutz, 2017) pelo conjunto das suas affordances comunicacionais - perceções individuais baseadas em características objetivas que o utilizador tem sobre determinado objeto (Gibson, 1979).

Destacam-se assim características distintivas de tais aplicações (1) mobilidade: as aplicações ao estarem instaladas no smartphone permitem desempenhar atividades privadas estando o utilizador, por exemplo, num espaço público; (2) proximidade: o funcionamento por geolocalização permite saber que outros utilizadores estão perto; (3) imediatez: o utilizador é informado sobre um novo match ou uma mensagem impulsionando o encontro (Duguay, 2016; Licoppe, Riviére e Morel, 2016; Hjorth, 2013); (4) autenticidade: possibilidade de o perfil ser criado através do Facebook (Duguay, 2016); e (5) predominância visual: as imagens são o cartão de visita, ocupando todo o ecrã do telefone e o texto considerado secundário (Chan, 2017; Duguay, 2016; Vieira e Sepúlveda, 2017).

De acordo com os dados disponíveis sobre Portugal e referentes ao ano de 2017 (Statista, 2019), o número de utilizadores de redes de online dating somava 530000 contas ativas, sendo que eram aqueles que se identificavam como sendo do género masculino quem mais utilizava este tipo de plataformas: $73,5 \%$ versus $26,5 \%$ do género feminino. No que dizia respeito à faixa etária, $39,5 \%$ pertencia ao grupo entre os 25-34 anos, seguindo-se aqueles entre os 35-44 anos com $29 \%$ dos utilizadores, em terceiro os utilizadores entre os 18-24 anos com uma representatividade de $17,3 \%$ e, por último, aqueles entre os 45-54 anos com um peso de $14,2 \%$.

Entre a oferta disponível, o Tinder acumulava o maior número de downloads na App Store em todo o mundo (Statista, 2016) estabelecendo-se como um meio através do qual é possível constituir relacionamentos de diferentes formatos ou durações (Chan, 2017). Está classificado na App Store como uma aplicação "estilo de vida" e em Portugal está entre as 4 aplicações com maior número de downloads, dentro desta mesma categoria (App Annie, junho 2019). 


\section{O QUE É O TINDER ${ }^{1}$}

O Tinder foi lançado originalmente para smartphone em 2012, aspeto que lhe confere um fator distintivo na sua utilização face aos sites, e a versão para computador surgiu em 2017. A utilização requer a criação de um perfil, sendo que o utilizador deverá ter no mínimo 18 anos. Os perfis, com informação limitada e onde a componente visual é privilegiada face à textual (Vieira e Sepúlveda, 2017), podem ser criados através do perfil da rede Facebook, onde a aplicação vai recolher informações como o nome, idade, escola, trabalho e as últimas seis fotografias de perfil, através do número de telemóvel ou conta Google onde essas informações são introduzidas manualmente. $\mathrm{O}$ registo é gratuito, no entanto, o utilizador pode recorrer a micropagamentos ou assinaturas mensais. Dependendo do plano de pagamento, o utilizador acederá a outras funções entre as quais se encontram número de gostos ilimitados, possibilidade de retroceder decisões, um boost - função que permite destacar o perfil durante 30 minutos - por mês, ou saber quem gostou do perfil do utilizador antes deste tomar uma decisão.

Funciona por geolocalização e após serem definidos critérios de procura (distância na qual quer procurar outras pessoas e em função de onde se encontra, idade e género), são devolvidos resultados que podem ser comunicados através de notificações ou quando o utilizador abre a aplicação.

No ecrã surge uma fotografia juntamente com o nome e idade do utilizador correspondente aos critérios estabelecidos. Caso o utilizador deseje saber mais sobre aquele perfil poderá deslizar o ecrã para visualizar as restantes fotografias ou pressionar no símbolo "i" para ler a informação. Caso o perfil seja do interesse do utilizador, este deverá deslizar o ecrã para a direta (swipe right) ou premir o símbolo "coração", caso pretenda descartar um certo perfil deverá deslizar o ecrã para a esquerda (swipe left) ou carregar no símbolo cruz.

Só após correspondência mútua, o match, é que os utilizadores poderão comunicar entre si, tentando mitigar que tenham de lidar com solicitações ou contactos inconvenientes (Timmermans e De Caluwé, 2017).

\section{MOTIVAÇÕES PARA O USO DO TINDER}

Os estudos no campo disciplinar das ciências da comunicação sobre as motivações que conduzem ao uso de aplicações de dating têm recorrido sobretudo à teoria dos usos e gratificações para analisar e enquadrar os resultados

1 Devido às constantes atualizações da aplicação os autores informam que a análise foi realizada em janeiro de 2019. 
encontrados (Gudelunas, 2012; Van De Wiele e Tong, 2014; Timmermans e De Caluwé, 2017). Um dos objetivos da teoria dos usos e gratificações é compreender por que é que os utilizadores procuram determinados media com o propósito de satisfazerem determinadas necessidades (Katz, Blumler, e Gurevitch, 1973; Palmgreen, Wenner e Rosengren, 1985; Rubin, 1994). Embora a teoria tenha sido inicialmente desenvolvida e aplicada aos chamados media tradicionais, com o surgimento da internet e das diferentes soluções de media sociais, onde estão incluídas as plataformas de online dating, o campo expandiu-se (LaRose e Eastin, 2004), considerando aspetos como o facto de o utilizador poder escolher o medium que melhor se adequa às suas necessidades e existindo uma maior interatividade da sua parte.

Através da teoria dos usos e gratificações são identificadas três categorias: as físicas, as sociais e as psicossociais (Sumter, Vandenbosch e Ligtenberg, 2016), onde se podem enquadrar os motivos de utilização de aplicações de online dating (Van De Wiele e Tong, 2014). As motivações físicas estão associadas com a gratificação sexual (Diamond, 2004; Patrick, Maggs e Abar, 2007; Van De Wiele e Tong, 2014). Parte-se do pressuposto de que é mais provável um utilizador do Tinder com motivações sexuais recorrer ao mesmo se tais desígnios forem gratificados (Gudelunas, 2012; Sumter, Vandenbosch e Ligtenberg, 2016; Timmermans e De Caluwé, 2017).

As gratificações sociais estão relacionadas com a perceção de alargamento da rede de contactos e, como tal, das possibilidades de encontro de parceiros com quem estabelecer relações (Hart, 2015; Park, Kee e Valenzuela, 2009), sejam estas de carácter duradouro ou não (Sumter, Vandenbosch e Ligtenberg, 2016), ou desenvolvimento de amizades (Gudelunas, 2012; Van De Wiele e Tong, 2014). Já as psicossociais incluem variáveis sociais como a aceitação ou a valorização pessoal (Nesi e Prinstein, 2015; Yurchisin, Watchravesringkan e McCabe, 2005), satisfazendo necessidades como sentimento de pertença, inclusão ou bem-estar (Gudelunas, 2012; Lawson, 2006; Van De Wiele e Tong, 2014). Um utilizador que procura aumentar a sua autoestima poderá satisfazer essa necessidade através dos matchs que alcança (Nesi e Prinstein, 2015).

Dos estudos realizados emergiram uma série de motivações, mais ou menos específicas, para o uso de aplicações de online dating. Van de Wiele e Tong (2014) identificaram um grupo de motivações através da realização de um questionário aos utilizadores da aplicação Grindr, onde estes eram convidados a descrever os motivos de uso. Sumter, Vandenbosch e Ligtenberg (2016) agregaram um conjunto de indicadores, resultado de um questionário online, onde os utilizadores do Tinder indicavam razões para o uso da aplicação e cuja proposta final consolidou 6 motivos (amor, sexo casual, facilidade de comunicação, validação de auto-estima, emoção e moda). Esta proposta 
final foi construída com a articulação de resultados obtidos com estudos de social media, internet dating e comportamento sexual online, sendo depois conduzida uma análise fatorial exploratória. Ranzini e Lutz (2017) recorreram ao trabalho de Van de Wiele e Tong (2014) adaptando-o para estudar os utilizadores do Tinder, construindo, por sua vez, uma nova série de motivações. Entre estas são comuns: socializar, sexo, validação pessoal, ou entretenimento.

Por fim, Timmermans e De Caluwé (2017) contribuíram com um resultado mais volumoso, composto por 13 motivações e 58 subitens, estando na sua origem a triangulação entre um estudo qualitativo e três quantitativos.

Os resultados desses estudos demonstraram que as motivações vão mais além da procura por sexo casual, sendo o amor/relacionamentos e a socialização apontados também como outras motivações principais para o uso deste tipo de aplicações (Sumter, Vandenbosch e Ligtenberg, 2016; Timmermans e De Caluwé, 2017). Entre estes estudos também emergiram diferenças de género (Abramova et al., 2016; Sumter, Vandenbosch e Ligtenberg, 2016): o masculino considerava a aplicação uma oportunidade para relações fugazes, enquanto o feminino considerava-a uma oportunidade para conhecer amigos ou um potencial parceiro com quem casar. Por fim, questões como valorização pessoal e entretenimento foram também identificadas como motivações para o uso da aplicação (Sumter, Vandenbosch e Ligtenberg, 2016; Timmermans e De Caluwé, 2017).

Estes contributos permitiram-nos conhecer quais os resultados sobre motivações para o uso de aplicações de dating, porém nestas análises não foram enquadradas as histórias de vida dos utilizadores que poderiam contextualizar as motivações identificadas. Desconhece-se o porquê dessas mesmas motivações, se as mesmas são exclusivas/estanques, se se alteram ao longo do tempo e da utilização, mas também que eventos podem ter motivado ou condicionado o uso da aplicação. Para tal seria importante ter em consideração a biografia dos utilizadores, nomeadamente acontecimentos específicos, e de que forma estes contextualizam as motivações.

\section{CURSO DE VIDA: OS TURNING POINTS}

O curso de vida, como sugerido por Giele e Elder (1998), traduz-se numa "sequência de eventos e papéis socialmente definidos que o indivíduo realiza ao longo do tempo" (p.22), à medida que experiencia um conjunto de acontecimentos que poderão ser de diferentes naturezas e intensidades.

Dependendo do efeito que tais acontecimentos tenham em redirecionar o curso de vida dos indivíduos, estes podem ser classificados como turning points 
(Nico, 2016). O conceito de turning points é usado para assinalar "momentos no percurso biográfico que geram uma mudança de orientação da trajetória individual" (Caetano, 2018, p. 91), podendo potencializar ou diminuir a acessibilidade e o contacto com outros, moldando as redes sociais pessoais e, consequentemente, impactar também a forma, o formato e o meio através do qual o indivíduo poderá socializar e iniciar relacionamentos.

Os turning points, conceito habitualmente aplicado em associação com a expressão life events (Rönka, Oravala, e Pulkknen, 2003), podem ter origem em acontecimentos positivos ou negativos, e suceder de forma voluntária ou involuntária (Teruya e Hser, 2010; Nico, 2016).

Na sua origem estão mudanças que podem ser classificadas de níveis macro a micro, onde se incluem acontecimentos de ordem económica ou social, relações com os outros, relações no âmbito do ambiente familiar ou questões pessoais, tanto do desenvolvimento pessoal como da personalidade (Nico, 2016; Wood, et al., 2017). Tais acontecimentos têm a capacidade de marcar de diferentes formas e intensidades as histórias pessoais dos indivíduos.

A identificação do(s) acontecimento(s) que pode $(\mathrm{m})$ produzir e consequentemente constituir estes turning point não é uma tarefa simples, nem de caráter definitivo (Teruya e Hser, 2010). O desafio na identificação está relacionado com o facto de o(s) acontecimento(s) ocorrido(s) estar(em) dependente(s) da perceção individualizada e não generalizável do sujeito face ao efeito do mesmo (Nico, 2016).

A esse aspeto soma-se a temporalidade em que determinado(s) acontecimento(s) possa(m) ser percebido(s) pelos indivíduos como turning points. Alguns são-no de forma imediata, porém outros apenas são classificados como tal após o decorrer de um período de tempo em que a mudança provocada no percurso se comprova (Teruya e Hser, 2010).

A complexificar ainda mais, também na origem dos turning points poderá estar um acontecimento específico e que o indivíduo identifica como impulsionador, ou um conjunto de acontecimentos, de mudanças, que vão ocorrendo e que podem ter resultados cumulativos, chegando o momento em que provocam uma transformação (Teruya e Hser, 2010).

Tendo em conta a variedade de acontecimentos que podem ser considerados por alguns indivíduos, mas não por outros, como turning points, as características pessoais e contextuais em que tais acontecimentos ocorrem estão também na base da explicação para a classificação dos mesmos (Teruya e Hser, 2010).

A classificação de um acontecimento como turning point, por um determinado indivíduo, reflete também os princípios da teoria do curso de vida: os contextos históricos e sociais do acontecimento; o momento da vida do 
indivíduo em que o acontecimento tem lugar; como as vidas estão vinculadas (linked lives), como os acontecimentos são refletidos nos seus relacionamentos sociais e a agência humana, na medida em que os indivíduos fazem escolhas e constroem as suas trajetórias (Giele e Elder, 1998; Quinn, 2012).

Desta forma, é salientada a importância do contexto e biografia dos indivíduos pela teoria do curso de vida aquando do significado atribuído por estes aos acontecimentos que experienciam e, consequentemente, a classificação de tais acontecimentos em turning points, tendo em conta o momento do curso de vida, mas também o estágio do ciclo de vida em que os indivíduos se encontram (Hutchison, 2011).

Nos diferentes estágios contemplados pela abordagem do ciclo de vida, o referente à idade adulta, que inclui os jovens adultos e os adultos de meia idade, é caracterizado como um período onde se registam um conjunto de eventos que produzem mudanças nos papéis desempenhados e consequentemente readaptações nas expectativas sociais (Hutchison, 2011).

$\mathrm{Na}$ fase dos jovens adultos existe uma maior oportunidade para exploração do eu em áreas laborais e amorosas (Arnett, 2004), traduzindo-se em acontecimentos como o primeiro trabalho a tempo inteiro ou relacionamentos que podem resultar em casamento ou parentalidade, ainda que essas transformações não sejam lineares na medida em que acontecimentos como o casamento ou nascimento de filhos têm sido substituídos por trajetórias múltiplas, incluindo novas variáveis e desafios na trajetória (Nico, 2016).

Já na fase dos adultos de meia-idade, é esperada alguma estabilidade em termos sociais, económicos e ocupacionais (Dolberg e Ayalon, 2018). É, tendencialmente, marcada pelo auge da carreira (Helson, Soto e Cate, 2006), mas também na qual o indivíduo se depara com desafios a nível sentimental enfrentando realidades como o divórcio, temporadas de luto e a possibilidade de refazer a sua vida, coordenando múltiplos papéis.

No contexto do curso de vida e no decurso da mudança de papéis, também se alteram as formas de consumo das tecnologias digitais. O recurso a estas tecnologias é influenciado por estilos de consumo, padrões ou preferências, de acordo com objetivos e procurando satisfazer necessidades (Katz, Blumler, e Gurevitch, 1973; Ruggiero, 2000).

O recurso à internet para fins específicos e onde incluímos as aplicações de online dating, poderá ser influenciado por estágios e eventos específicos da vida do indivíduo tais como mudança de local de trabalho, geográfica ou até de estado civil (Quinn, 2012). No contexto dos relacionamentos e amizades, etapas da vida e acontecimentos relacionados com a educação, a família ou trabalho podem influenciar as experiências vividas. Adicionalmente, o início ou término de um relacionamento amoroso ou experiência de parentalidade são 
acontecimentos críticos no âmbito das estruturas sociais e que também podem ser interpretados como propulsionadores de mudanças.

Posto isto, a internet poderá constituir um meio para manter relacionamentos ou amizades, mas também para iniciar novas e o recurso à mesma pode ser contextualizado como resposta a mudanças produzidas nas anteriores (Spencer e Pahl, 2006).

Desta forma, a história pessoal e o seu desenvolvimento são aspetos fundamentais no recurso às tecnologias de online dating e na contextualização das motivações, nomeadamente porque os objetivos podem variar ao longo do curso de vida (Sassler, 2010), assim como poderá variar a gestão da intimidade de cada um.

Identificar os acontecimentos que levaram ao uso da aplicação Tinder no contexto das motivações pode ser particularmente interessante por facultar informações sobre os acontecimentos que potenciaram o recurso à tecnologia, acontecimentos esses que os indivíduos poderão classificar como propulsionadores de mudança(s).

\section{METODOLOGIA}

Tendo em conta a pergunta de partida que guiou esta investigação (quais os acontecimentos na vida dos utilizadores que conduziram ao uso do Tinder e as motivações subjacentes a esse uso) e o conjunto de objetivos definidos que consistiam em (1) identificar os turning points que conduziram ao recurso ao Tinder (2) identificar as motivações para o uso e (3) contextualizar as motivações tendo em conta os turning points identificados pelos utilizadores, recorreu-se a entrevistas semiestruturadas no quadro de uma metodologia qualitativa-intensiva.

O facto de estas serem semiestruturadas (Bryman, 2012), e realizadas com base num guião previamente estabelecido, conferiu a possibilidade de condução de recolha de dados discursivos com uma maior flexibilidade em função do decurso de cada conversa. Permitiu mesmo a inclusão de perguntas segundo informações geradas pelos próprios entrevistados, certificando-nos de que todas as questões eram respondidas, mas evitando repetições. O guião era composto por duas grandes dimensões de análise: (1) motivações para usar a aplicação (2) eventos na biografia que conduziram ao uso.

Tendo em conta que a temática em análise incide sobre assuntos íntimos dos entrevistados, privilegiou-se a realização de entrevistas face a face, já que o resultado das mesmas poderia beneficiar da proximidade entre a investigadora e a/o participante. Porém, e ainda que a riqueza do contexto não seja semelhante, também se realizaram entrevistas audiovisuais online com 
recurso ao Skype. Através desta solução mediada foram eliminados constrangimentos geográficos ou temporais, sendo também conferida aos participantes uma maior sensação de segurança, não se sentido tão expostos (Couch, Liamputtong e Pitts, 2012; Lo Iacono, Symonds e Brown, 2016).

Entre dezembro de 2017 e janeiro de 2019 foram recrutados utilizadores portugueses da aplicação através da criação de perfis no Tinder, seguindo a estratégia utilizada por outros investigadores (Blackwell, Birnholz, e Abbott, 2015; Ward, 2016) e nos quais se indicava o recrutamento de utilizadores com o fim de participarem num estudo académico referindo as instituições de afiliação. Simultaneamente, foi colocada uma entrada no Reddit ${ }^{2}$, foi criada uma página no Facebook, uma conta no Instagram e um site onde se divulgava o estudo, solicitando a participação e a divulgação segundo efeito em bola de neve. Finalmente, através de um inquérito online que se estava a realizar no âmbito da investigação, e dirigido a utilizadores de plataformas de dating, foi deixado um campo para contacto, caso os utilizadores estivessem interessados em participar numa entrevista.

Os potenciais interessados teriam de ser utilizadores portugueses ativos do Tinder ou terem utilizado a aplicação nos últimos 12 meses. Estabeleceu-se este prazo devido às mudanças constantes que vão ocorrendo na aplicação. Em resposta à divulgação, os interessados eram contactados via e-mail, através do qual se explicava em que consistia o estudo e que deveriam estar disponíveis para uma entrevista, sendo esta agendada de acordo com a disponibilidade dos mesmos. Antes da sua realização, informou-se os participantes de que a entrevista seria gravada e solicitou-se o preenchimento do consentimento informado.

Durante os 13 meses de recrutamento, foram entrevistados 27 participantes, 23 face a face e 4 por Skype, e as entrevistas duraram entre 20 e 88 minutos, sendo o conteúdo transcrito e analisado com recurso ao software MaxQda. Esta diferença na duração das entrevistas deveu-se ao ritmo das mesmas, à capacidade de concisão do entrevistado, especificamente em relação à sua história de vida e ao nível de informação partilhada. $\mathrm{Na}$ análise dos resultados teve-se em consideração o facto de as entrevistas terem sido realizadas por uma investigadora, o que gerou inibições por parte de alguns participantes do sexo masculino em revelarem os seus motivos, assim como um certo tabu ainda associado ao uso da aplicação e consequentes julgamentos.

Os dados foram interpretados recorrendo à análise temática, permitindo identificar, analisar e criar padrões (Braun e Clark, 2006) considerando teoria e resultados já existentes. Procedeu-se à codificação dos dados gerados a

2 O Reddit é um site cujo funcionamento se assemelha a um fórum público no qual os utilizadores registados podem colocar entradas e comentar. 
partir da interação entre a entrevistadora e os participantes como resposta às suas questões - elicited data (Salmons, 2016) -, das quais emergiram um conjunto de categorias organizadas num livro de códigos, de acordo com as duas dimensões em análise: motivações e turning points, com a respetiva descrição e citação a modo de exemplo (Creswell, 2013).

\section{RESULTADOS}

A amostra por conveniência foi composta por 27 utilizadores da aplicação Tinder, entre os quais 12 se identificaram como sendo do género feminino e 15 do género masculino, com idades compreendidas entre os 19 e os 54 anos e distribuídos de acordo com o quadro 1.

Os entrevistados caracterizavam-se por, na sua maioria, terem formação superior $(n=21)$, estarem a trabalhar à data da realização da entrevista $(n=19)$, em situação de desemprego $(n=3)$ ou a estudar $(n=5)$. De entre os 27 participantes, 24 identificaram-se como heterossexuais, 2 como bissexuais e 1 como homossexual. 13 entrevistados indicaram que viviam sozinhos, 4 com os pais, 5 partilhavam casa com colegas ou amigos, 4 viviam com o(s) filho(s) e 1 com o namorado/a. Por fim, 21 indicaram que não tinham filhos.

Quando questionados sobre há quanto tempo usavam a aplicação, as respostas variaram entre 3 semanas e 5 anos. Sendo que, no momento da entrevista, dos 27 participantes 20 estavam a utilizá-la e sete indicaram que não. Entre estes últimos, quatro tinham mesmo desinstalado a aplicação.

Entre as motivações apontadas pelos participantes como razão para usar o Tinder, registaram-se os três tipos de gratificações contempladas pela teoria dos usos e gratificações: sociais, psicossociais e físicas. Como se pode verificar na nuvem de frequências apresentada na figura 1, entre o conjunto de motivações identificadas "socializar", "procura de relacionamentos" e recurso ao Tinder para encontrar alguém com quem ter "sexo" foram aquelas maioritariamente referidas. Estas motivações vão ao encontro do resultado de outros estudos realizados, permitido afirmar que o uso Tinder é, de acordo com os entrevistados, vocacionado para mais do que a procura de sexo ou relações fugazes intimamente ligadas a gratificações físicas (Sumter, Vandenbosch e Ligtenberg, 2016; LeFebvre, 2017; Timmermans e De Caluwé, 2017), mas principalmente para obter gratificações de ordem social.

O ambiente criado pelos media com notícias sobre a aplicação (Sepúlveda e Vieira, 2019), o uso por amigos e conversas sobre o assunto suscitaram o interesse sobre o funcionamento do Tinder e sobre quem se poderia lá encontrar. Assim, 21 participantes referiram a motivação "curiosidade" como fator impulsionador para a instalação. 
QUADRO 1

Caracterização da amostra

\begin{tabular}{|c|c|c|c|c|c|c|c|c|}
\hline & Grupo etário & $19-24$ & $25-30$ & $31-36$ & $37-42$ & $43-48$ & $49-54$ & Total \\
\hline & $\mathrm{n}$ & 5 & 5 & 10 & 1 & 3 & 3 & 27 \\
\hline \multirow{2}{*}{ Género } & Feminino & 0 & 4 & 5 & 0 & 2 & 1 & 12 \\
\hline & Masculino & 5 & 1 & 5 & 1 & 1 & 2 & 15 \\
\hline \multirow{2}{*}{$\begin{array}{l}\text { Escola- } \\
\text { ridade }\end{array}$} & $12^{\circ}$ ano & 2 & 0 & 2 & 0 & 0 & 2 & 6 \\
\hline & Superior & 3 & 5 & 8 & 1 & 3 & 1 & 21 \\
\hline \multirow{3}{*}{$\begin{array}{r}\text { Orientação } \\
\text { Sexual }\end{array}$} & Heterossexual & 4 & 5 & 9 & 0 & 3 & 3 & 24 \\
\hline & Homossexual & 1 & 0 & 0 & 0 & 0 & 0 & 1 \\
\hline & Bissexual & 0 & 0 & 1 & 1 & 0 & 0 & 2 \\
\hline \multirow{2}{*}{$\begin{array}{r}\text { Estado } \\
\text { civil }\end{array}$} & Solteiro & 5 & 5 & 10 & 1 & 0 & 0 & 21 \\
\hline & Divorciado & 0 & 0 & 0 & 0 & 3 & 3 & 6 \\
\hline \multirow{2}{*}{ Filhos } & Tem & 0 & 3 & 0 & 0 & 3 & 2 & 6 \\
\hline & Não tem & 5 & 2 & 10 & 1 & 0 & 0 & 21 \\
\hline \multirow{5}{*}{$\begin{array}{c}\text { Com } \\
\text { quem } \\
\text { vive }\end{array}$} & Sozinho & 1 & 2 & 7 & 0 & 1 & 2 & 13 \\
\hline & Pais & 4 & 0 & 0 & 0 & 0 & 0 & 4 \\
\hline & Filhos & 0 & 1 & 0 & 0 & 2 & 1 & 4 \\
\hline & Amigos/colegas de casa & 1 & 2 & 2 & 0 & 0 & 0 & 5 \\
\hline & Namorado & 0 & 1 & 0 & 0 & 0 & 0 & 1 \\
\hline \multirow{4}{*}{$\begin{array}{r}\text { Situação na } \\
\text { profissão }\end{array}$} & Conta própria & 1 & 1 & 0 & 0 & 1 & 3 & 6 \\
\hline & Conta de outrem & 0 & 3 & 7 & 1 & 2 & 0 & 13 \\
\hline & Desempregado & 0 & 1 & 1 & 1 & 0 & 0 & 3 \\
\hline & Estudante & 4 & 1 & 0 & 0 & 0 & 0 & 5 \\
\hline
\end{tabular}

Fonte: Elaboração própria dos autores.

A motivação "Passar o tempo" surgiu da lógica de utilização, que através da estratégia de gamificação levava o utilizador a ligar-se várias vezes e a estar expectante perante os resultados: match e mensagens, bem como de um ritual de utilização na medida em que participantes referiram que consultavam o Tinder da mesma forma que consultavam outras redes sociais, como passatempo, no sentido de colmatar momentos em que não tinham nada para fazer - por exemplo, depois de jantar e antes de irem dormir entretinham-se a ver perfis.

Entre as gratificações de natureza psicossocial, usar o Tinder para satisfazer necessidades relacionadas com a "pertença" e a "aprovação social" foram as que mais se destacaram. Nomeadamente, poder fazer parte das conversas 
que ocorriam entre os grupos de pares sentindo-se integrados, mas também sentir-se valorizado por terceiros foram argumentos apresentados pelos participantes.

Com menos destaque, mas igualmente importante é o uso da aplicação devido a "pressão dos pares" que se traduziu numa insistência não só em usar, mas também em permitir que outros criassem os seus perfis, ou usar o Tinder para melhorar "habilidades sociais" nomeadamente entre os que se consideravam tímidos justificando que por se tratar de um meio mediado, o ecrã reduzia alguma timidez.

Não se registaram participantes que referiram usar o Tinder apenas com uma única motivação, da mesma forma que estas se podiam ir alterando ao longo do tempo de uso, mas também tendo em conta as experiências vividas através da mesma. A teoria dos usos e gratificações defende que a satisfação da necessidade era motivo para continuar a usar o meio (Ruggiero, 2000).

Na figura 2 refletem-se os resultados relativos à dimensão de eventos ocorridos ao longo da trajetória de vida dos participantes. Os turning points mais referidos refletiam acontecimentos no curso de vida individual tais como estar

FIGURA 1

Nuvem de frequências relativa à dimensão motivações.

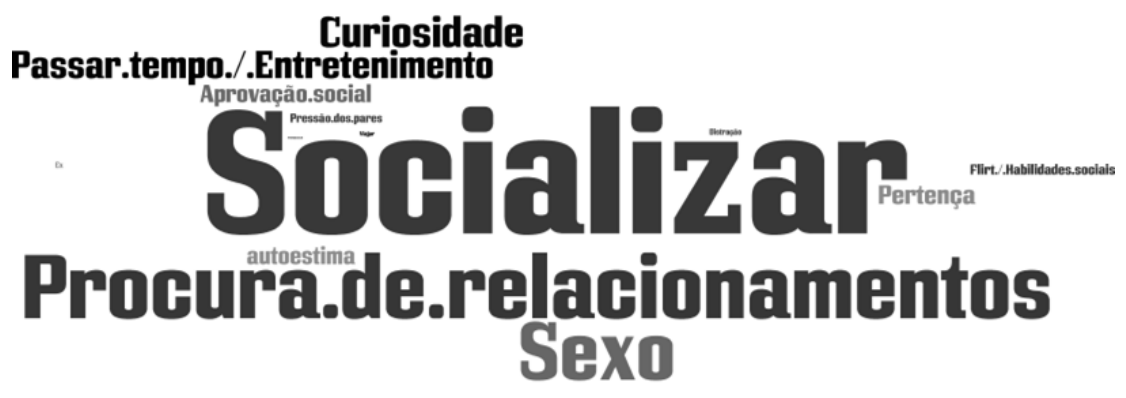

Fonte: Elaboração própria dos autores.

FIGURA 2

Nuvem de frequências relativa aos acontecimentos identificados como turning points

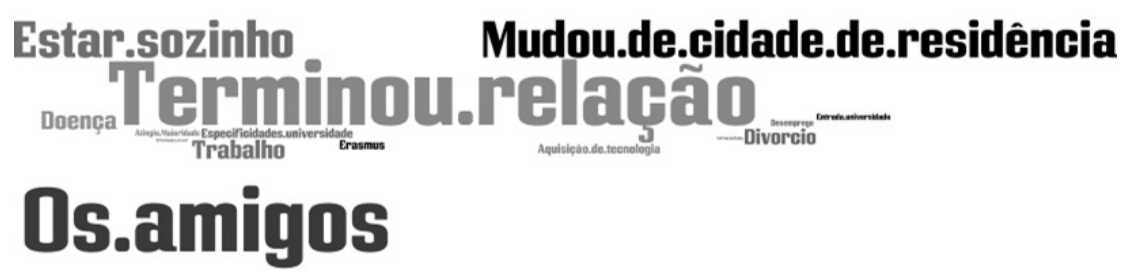

Fonte: Elaboração própria dos autores. 
sozinho, o fim de uma relação, mudança de cidade de residência (motivada por questões escolares ou profissionais) e cujos períodos de tempo tinham diferentes durações. Mas também alterações ocorridas no âmbito do círculo de amigos, onde se incluem o compromisso/casamento ou parentalidade por parte destes. Como sugerido por Hutchison (2011), eventos de diferentes naturezas podem originar diferentes impactos na vida dos indivíduos e consequentemente diferentes resultados como resposta aos mesmos.

Questões relacionadas com a esfera profissional, como o volume de tempo dedicado ao trabalho ou questões do âmbito escolar, como o início de um novo ciclo ou frequência de um novo estabelecimento de ensino, foram também acontecimentos identificados pelos participantes como instigadores do uso do Tinder.

No campo da saúde, a condição de doença (depressão ou doença crónica por exemplo) resultou num isolamento por parte dos indivíduos cuja consequência foi uma redução da rede relacional. Tal acontecimento levou-os a recorrerem ao Tinder como forma de estabelecer novos conhecimentos e poder ver satisfeitas necessidades de ordem social, psicossocial bem como de ordem física.

TINDER: UMA FERRAMENTA PARA “CONHECER PESSOAS", AUMENTANDO A REDE DE CONTACTOS E COMO RESPOSTA A EVENTOS OCORRIDOS

No cômputo geral das motivações identificadas pelos participantes como razão para usar o Tinder, "socializar" foi aquela que se destacou não só por ser referida por um maior número de entrevistados $(\mathrm{n}=23)$ como também por ser maioritariamente enfatizada nos discursos (85 registos entre os 27 participantes). Esta é uma das razões apontadas pela teoria dos usos e gratificações que justifica o recurso a determinado media e que vai ao encontro do resultado encontrado por outros estudos (Hart, 2015; Park, Kee, e Valenzuela, 2009; Sumter, Vandenbosch e Ligtenberg, 2016; Gudelunas, 2012; Van De Wiele, e Tong, 2014).

A noção de "socializar", definida in vivo pelos participantes como "conhecer pessoas", traduz uma das formas de domesticação (Silverstone et al., 1992) da aplicação pelos utilizadores refletindo não só as funções atribuídas às redes sociais online, como também um conjunto de potencialidades por estas geradas. Os participantes consideraram o Tinder uma ferramenta através da qual podiam ter acesso a outros indivíduos, sem recorrerem às redes consideradas tradicionais, como o seu grupo de amigos ou meios como a escola ou local de trabalho, quer por opção própria, quer por imposição. O recurso à aplicação foi considerado vantajoso pelos participantes na medida em que podiam não 
só alargar a sua rede de contactos como, através desta, aceder a um conjunto heterogéneo de pessoas.

Entrevistado 5 (39 anos, divorciado). No momento da entrevista tinha instalado recentemente o Tinder. Argumentou que tinha uma vida preenchida com o trabalho a ocupar-lhe grande parte do seu tempo e o pouco que tinha livre era dedicado a praticar desporto.

"É mais uma ferramenta para conhecer pessoas. (...) Eu gosto de conhecer pessoas. Isto para mim é como qualquer sítio para conhecer pessoas. Isto é só um meio.”

Entrevistada 16 (35 anos, solteira). Instalou o Tinder após se aperceber que a sua rede de amizades tinha diminuído durante o tempo no qual esteve numa relação.

"Tinha terminado um relacionamento e queria conhecer pessoas, primeiro para conhecer volume, por assim dizer, porque com o término da relação, os amigos também, muitos deles perderam-se, e eu queria conhecer mais pessoas."

Através destes dois relatos não só é ilustrada a importância do argumento "socializar", justificado pelo interesse dos participantes em usarem a aplicação com o intuito de conhecerem outras pessoas, mas também o significado e a dimensão atribuída a este. Registaram-se entre os participantes aqueles que procuravam conhecer pessoas do mesmo género, de géneros opostos ou ambos, os que buscavam conhecer estrangeiros por considerarem que este grupo poderia ser mais interessante na medida em que lhes proporcionariam momentos de lazer ou um aumento do seu capital cultural. Encontrámos também aqueles que procuravam quem lhes fizesse companhia para programas tão casuais como jogar computador, ir à praia, beber um copo, jantar ou conversar. O Tinder é assim interpretado como um meio através do qual os utilizadores conseguem alargar a sua rede de contactos e conhecer pessoas com interesses comuns, podendo esse encontro ser imediato devido às affordances da aplicação (Hjorth, 2013).

Foi percetível, através do discurso dos participantes, que o referido motivo para utilizar a aplicação estava associado a eventos ocorridos no âmbito da esfera emocional, como o culminar de um relacionamento ou divórcio e, como consequência, estarem sozinhos.

Entrevistado 9 (36 anos, solteiro). A instalação do Tinder, e de outras aplicações, ocorreu após terminar o namoro. Estando, no momento da entrevista, a usar a aplicação há um ano e meio.

"Estive a namorar até essa altura. Por regra tenho sempre relações longas. Sempre namoros de 5, 6, 7 anos, por aí. O último acabou nessa altura e uma pessoa ah, vou ver o que é que se passa nas Apps e foi isso." 
No referido contexto, registou-se também a menção de questões de satisfação de necessidades relacionadas com a autoestima. Através do uso da aplicação, gratificações de ordem psicossocial e relacionadas com a "aprovação social” eram satisfeitas. A instalação e consequente uso da aplicação era justificada pelos utilizadores por considerarem que através desta e da sua dinâmica de utilização, o facto de alcançar um match com outros utilizadores, significava que alguém os valorizava e isso fazia-os sentir bem consigo próprios, aumentando o seu ego e remetendo para questões de auto-validação ou aceitação, contempladas pela categoria psicossocial na teoria dos usos e gratificações (Sumter, Vandenbosch e Ligtenberg, 2016).

Entrevistado 3 (49 anos, divorciado). Teve conhecimento do Tinder através dos media $e$ instalou-o quando o divórcio se concretizou. Sentia-se desvalorizado e considerava que, devido à sua idade, não se iria envolver com mais ninguém tanto emocionalmente, como fisicamente.

"Eu estava com a autoestima muito em baixo. Estava a fazer um divórcio complicado e achava que realmente... eu estava com 46 anos na altura, tenho 49 agora e achava que... estava com a autoestima muito em baixo e achava que ia ficar por ali, que me ia dedicar aos filhos, à casa, à empresa, ao trabalho."

Para além de eventos ocorridos no contexto da esfera emocional, os participantes também referiram acontecimentos no âmbito da esfera social entre os quais aqueles relacionados com a mudança de residência, devido a motivos laborais ou escolares, tanto no contexto português como internacional. Fatores como não terem uma rede de amigos ou conhecidos no novo local e a dificuldade em integrar grupos de amigos já formados, aliado ao desejo de quererem conhecer outras pessoas, criava o ambiente que proporcionava a instalação da aplicação.

Entrevistada 22 (27 anos, solteira). O terminar do relacionamento e a mudança de cidade de residência, onde não conhecia praticamente ninguém, fez com que instalar o Tinder lhe parecesse a solução indicada.

"Foi o facto de ter terminado essa relação (...) e depois vim para Lisboa, ou seja, vim para uma cidade nova, amigos não tinha, muito poucos, pessoas que eu conhecia da licenciatura, muito poucos, trabalhava, ia ao ginásio. E eu pensei, eu tenho de arranjar maneira de conhecer pessoas porque eu não conheço ninguém aqui, não tenho grupo de amigos, não há aquela questão dos amigos dos amigos e depois pensei pronto, a melhor maneira é o Tinder, é para conhecer pessoas.”

Ainda no âmbito da esfera social e no contexto do recurso ao Tinder para conhecer pessoas, a importância e o papel atribuído à rede familiar não esteve 
presente no discurso dos participantes, tanto entre aqueles que afirmaram que os seus irmãos conheciam ou usavam, assim como aqueles que explicaram aos pais ou filhos no que consistia ou os que incentivaram de alguma forma a usar. Ao contrário da familiar, a rede composta pelos amigos assumiu significado entre os utilizadores ao darem a conhecer e partilharem experiências provenientes do uso da aplicação, mas também na medida em que a saturação da rede de amigos, a pouca heterogeneidade e a procura de fugir às rotinas nestas criadas e pelos elementos que as compunham, serviam como justificação para usar o Tinder.

Entrevistada 23 (25 anos, solteira). Já usou o Tinder em diferentes momentos da sua vida, com diferentes objetivos e motivações. Considera que a aplicação é uma boa forma de fugir do seu grupo de amigos e assim evitar rotinas criadas no mesmo.

"Estava um bocado farta das pessoas que estavam à minha volta, não farta de não gostar deles, mas farta de ser sempre no mesmo grupo, as mesmas rotinas, então achei que ia ser uma boa oportunidade para conhecer uma pessoa nova."

Entrevistada 25 (47 anos, divorciada). Instalou o Tinder recentemente (1 mês). Um dos seus grandes argumentos para usar está efetivamente relacionado com o querer sair do seu círculo de amigos.

"O meu meio está razoavelmente esgotado. As pessoas com quem eu me dou no quotidiano já não me interessam, portanto havia alguma sensação de querer sair desta esfera para conhecer gente nova. E gente nova em geral, e não só relacionamentos amorosos, nem sequer só para sexo."

Tendo em conta que o Tinder é uma aplicação de online dating, ao motivo "socializar" estavam associadas outras motivações de caráter considerado íntimo. No decorrer do discurso dos utilizadores, estes mencionavam a vontade de conhecer pessoas indicando que, dependendo do decorrer das conversas e dos possíveis encontros, poderiam estar disponíveis para "algo mais". Esse "algo" podia ser encontrar alguém com quem desenvolver um relacionamento $(n=18)$ ou com quem se pudessem envolver sexualmente $(n=16)$.

\section{PROCURA ONLINE DE RELACIONAMENTOS COMO RESPOSTA A MUDANÇAS NAS REDES SOCIAIS E LOCAIS TRADICIONAIS.}

No âmbito das gratificações sociais, que vão para além de conhecer alguém, surge o estabelecimento de relações. A procura de novos parceiros assume uma importância entre aqueles que instalaram o Tinder sendo, entre os participantes, a segunda motivação mais referida $(n=18)$. 
O tipo de relacionamento procurado poderia ser de caráter não definido, traduzindo-se apenas em encontrar alguém com quem estar, sem objetivos concretos ou definidos a médio ou longo prazo, mas no polo oposto, a procura de um relacionamento assumiu um caráter mais sério e permanente como encontrar um/a namorado/a ou alguém para casar.

Entrevistado 15 (24 anos, solteiro). Ter lido sobre a aplicação e o facto de os amigos a usarem e comentarem as suas experiências impulsionaram a instalação da aplicação.

"Instalei a aplicação com o objetivo de ver se podia encontrar lá alguém. Instalei para conhecer alguém (...) É, está aqui uma pessoa interessada em ter um relacionamento, eu cá estou interessado em ter um relacionamento, se estamos ambos interessados em ter um relacionamento, vemos se existe alguma espécie de interesse mútuo e aí o Tinder seria apenas a plataforma que diz existe a esta pessoa que existe aquela.”

Entrevistada 20 (38 anos, solteira). Não é a primeira vez que usa serviços de online dating para procurar alguém com quem ter uma relação. Apesar de as experiências anteriores não terem sido muito satisfatórias e ter algumas reticências sobre a efetividade dos serviços, a popularidade do Tinder, aliada ao facto de estar sozinho, levou a que o instalasse.

"Não estou com ninguém neste momento e gostava de ter um relacionamento."

Todos os divorciados identificaram o divórcio como um turning point, após o qual o uso da aplicação era normalizado. Contudo, há diferenças nas motivações. Apenas o mais novo, 35 anos, referiu que equacionava o uso do Tinder para encontrar alguém com quem ter um relacionamento duradouro. Já os restantes procuravam algo a que não estivesse associado compromisso ou permanência, questionando a necessidade de exclusividade relacional.

Em sintonia com investigações anteriores que denotaram que a separação ou o divórcio tem consequências na gestão da habitação (Feijten e Mulder, 2010), os participantes justificavam as suas escolhas argumentando já não estarem disponíveis para dividir casa com alguém e que não pretendiam refazer a vida. Procuravam sim ter alguém com quem pudessem socializar ou envolver-se sexualmente. Em concordância com os mesmos autores, que defendem que a linearidade dos padrões de relacionamentos tem diminuído ao longo do curso de vida (Feijten e Mulder, 2010).

Entrevistado 2 (54 anos, divorciado). Instalou o Tinder há cerca de quatro anos, quando a última relação terminou. Argumenta que o Tinder é a aplicação mais usada, portanto onde está mais gente.

"Eu vivo sozinho há quatro anos, os dois primeiros anos foram muito complicados, mas agora estou naquelas situações em que penso muitas vezes assim, eu não sei se vou voltar a 
viver com outra pessoa. Já estou tão estável sozinho e já me habituei tanto e a gostar tanto de ter a minha vida sozinho."

Entrevistada 19 (45 anos, divorciada). Não quer compromissos nem rotina, procura alguém que saiba estar e que tenha uma conversa interessante. Com quem seja agradável estar, porém descarta relacionamentos rotineiros.

" $\mathrm{Eu}$, no meu caso, está fora de questão querer ir casar outra vez ou viver com alguém, isso também está nas minhas frases. Não quero viver com ninguém... também não sou fácil. Eu basicamente quero alguém para ir passar uns fins de semana fora, ponto. Não quero mais nada."

À semelhança daqueles utilizadores que procuravam conhecer pessoas, identificou-se entre os que procuravam um relacionamento, um conjunto de eventos na trajetória de vida destes que conduziram à instalação do Tinder. Ter terminado uma relação e estar sozinho voltaram a destacar-se entre os turning points identificados.

Entrevistado 12 (19 anos, solteiro). Considera que nunca teve muito sucesso entre as raparigas. Teve uma namorada há 2 anos, mas a relação terminou.

"Uma das motivações principais que tenho era encontrar alguém, conseguir ter alguma conexão já que o destino não o faz, então vai uma aplicação de telemóvel fazer (...) o que eu pretendia mesmo era namorar, mas se não for, entretanto, ok... embora, por acaso pensado assim mais sobre o assunto, não me agrada muito a ideia. Prefiro coisas sérias.”

Não obstante, entre os participantes com idades compreendidas entre os 19 e os 24 anos que procuravam relacionamentos, foram relatados acontecimentos que marcaram o contacto com o Tinder, nomeadamente a entrada na faculdade e a composição específica do ambiente académico, como por exemplo existirem mais homens do que mulheres, atingir a maioridade (que permitia usar a aplicação) ou frequência do programa Erasmus.

Entrevistado 1 (21 anos, solteiro). Quando fez 18 anos um amigo, que usava, falou-lhe do Tinder e ele instalou.

"Eu lembro-me que instalei a aplicação em dezembro de 2014, mais ou menos, para ficar até hoje. Dezembro de 2014, foi o ano em que entrei na universidade."

O grupo de amigos assumiu uma maior prevalência na contextualização do recurso ao Tinder para a procura de relacionamentos. Os amigos foram, em parte, responsáveis não só por darem a conhecer a aplicação, mas por desmistificarem e até normalizarem o seu uso. Essa partilha pode aguçar a 
curiosidade e tende a ser tópico de conversas. Trata-se de uma questão de integração e sentimento de pertença grupal. As experiências positivas partilhadas pelos elementos dos grupos e incitação surgiram também como forma de motivação para o uso da aplicação.

Entrevistado 8 (22 anos, solteiro). Os amigos usavam e falavam sobre o uso e quando foi de Erasmus, decidiu instalar com a ideia de se divertir. Já em Portugal foi com a ideia de encontrar alguém com quem ter um relacionamento que voltou a usar.

"Comecei pela piada a utilizar há dois anos em Erasmus, o resto dos meus colegas tinham todos e foi tipo vamos lá ver qual é a excitação toda. (...) O Tinder quando muito seria para colmatar essa falta de relações (...) Seria conhecer alguém, ou ter uma relação, uma cena assim do género. Seria esse o principal objetivo."

Respostas a acontecimentos no grupo de amigos também foram interpretados como turning points, nomeadamente o início de relacionamentos no grupo de amigos. Este é um aspeto particularmente importante no início da adultez. Período geralmente marcado pelo desenvolvimento de relações íntimas e no qual é expectável o desenvolvimento de relações que podem levar ao estabelecimento de relacionamentos mais sérios, ao viver conjuntamente e ao casamento ou união de facto, à medida que é explorada a identidade em áreas amorosas (Arnett, 2004).

Adicionalmente, a composição do grupo de amigos e identificação de limitações para uma potencial relação - tais como o reduzido número e o não interesse/vontade em estabelecer relações intragrupais - eram fatores apontados pelos participantes como justificações para instalar o Tinder. Ainda dentro da composição o facto de alguns dos amigos já estarem comprometidos, casados ou com filhos foi apontado como outra condicionante.

Entrevistada 26 (33 anos, solteira). Amigos falaram-lhe sobre o Tinder e ficou mais interessada quando uma amiga lhe contou que se ia encontrar com um utilizador. Já teve mais do que um relacionamento com alguém que conheceu através da aplicação.

"O que eu queria era o amor da minha vida, era o que eu andava à procura (...) o meu grupo de amigos tinha-se modificado um bocadinho, havia gente que já estava muito em casais e gente que já tinha filhos (...) os círculos de amigos já eram um bocadinho viciados e já não vem muito mais gente nova, e quem já lá está se não deu antes, não vai dar agora."

Para além das redes familiares e de amizades, também emergiram nos resultados aspetos contextualizadores do uso da aplicação relacionados com o contexto laboral. Se por um lado surgiram considerações no discurso como uma perceção de o local de trabalho não ser indicado para envolvimento 
com colegas, chegando a descartar perfis de utilizadores que trabalhavam no mesmo local, o oposto também se verificou: encontrar um colega de trabalho e abordá-lo na esperança de poderem iniciar uma conversa.

Entrevistado 7 (32 anos, solteiro). Está disponível para encontrar uma pessoa com quem se envolver sentimentalmente, mas tem dúvidas que a encontre no Tinder.

"A empresa onde eu trabalho é relativamente grande. Eu não gosto muito de envolver-me com pessoas daquele meio, mas a única regra que tenho é não me envolver com alguém que seja da mesma hierarquia, aí já misturava demasiado.”

Também se verificaram relatos de situações em que conhecer alguém era mais difícil, como por exemplo no caso dos trabalhadores por conta própria, por não estarem inseridos diariamente em ambientes com outras pessoas. De forma análoga, os participantes que se encontravam desempregados $(\mathrm{n}=3)$ referiram que recorriam ao Tinder devido à condição que estavam a viver, que de certa forma os isolava.

Noutro prisma, aqueles participantes com profissões de maior contacto social, mas nas quais desempenhavam funções junto de franjas etárias mais específicas, como por exemplo, menores ou seniores, relatavam igualmente essa dificuldade. Assim, tais acontecimentos, tipo de profissão ou situação de desemprego, são identificados pelos entrevistados como turning points.

Para além das redes sociais profissionais, através das quais os utilizadores poderiam conhecer novas pessoas, os participantes referiram que deixaram de frequentar locais como bares e/ou discotecas com esse intuito. Este acontecimento biográfico era transversal a participantes de diferentes idades, porém foram apontadas várias razões para esta atitude. Desde os que consideravam já não terem idade para frequentar bares/discotecas, isto entre os participantes mais velhos, passando pelos que estavam a trabalhar e relataram não terem tempo, até aos que consideraram não ser apropriado e não se quererem expor. Alguns apontaram ainda para experiências passadas não positivas, timidez ou mesmo "comodismo". Para todos estes a aplicação permitia conhecer novas pessoas sem "sair de casa".

Entrevistado 10 (35 anos, solteiro). Considera que está um pouco isolado. A situação de desemprego, o isolamento devido a doença e o facto de ser tímido, resultam, segundo o próprio, numa dificuldade em conhecer pessoas.

"Para alguém que sempre teve dificuldades em conhecer pessoas na vida real, como eu, aquilo na aparência torna-se mais fácil, porque é como se, imagine, se eu quero conhecer alguém lá fora, da maneira como se fazia antes do Tinder, do Facebook, tinha que ir sair à noite, tinha que ir a bares, tenho que fazer essas coisas todas e para mim é um bocado difícil 
fazer isso, eu já fiz isso, só que como eu sou um bocado tímido pensei que usando essas apps e aqueles sites e isso tudo torna-se um bocado mais fácil.”

\section{USAR O TINDER PARA SATISFAZER MOTIVAÇÕES FÍSICAS: PROCURAR ALGUÉM COM QUEM APENAS SE ENVOLVER SEXUALMENTE}

A utilização do Tinder para encontros sexuais foi a terceira motivação mais referida pelos participantes $(n=16)$ sendo que, entre estes, 4 inquiridos afirmaram que essa seria a principal motivação para utilizar a aplicação. Argumentavam que estavam interessados em conhecer pessoas, porém com um intuito unicamente sexual, explicando que não procuravam relacionamentos ou qualquer tipo de compromisso.

Apesar da aplicação ser apresentada oficialmente como uma plataforma para conhecer pessoas, esta é enquadrada pelos media portugueses (Sepúlveda e Vieira, 2019) enquanto facilitadora de encontros casuais e mesmo sexuais. Este tipo de enquadramento mediático servia de justificação para aqueles com uma motivação sexual para o uso da aplicação, argumentando que quem estava inscrito não deveria ficar admirado por encontrar utilizadores com este objetivo.

Entrevistada 21 (26 anos, solteira). Tinha terminado um relacionamento de seis anos. Os amigos insistiram para que instalasse o Tinder e a ideia foi, através da aplicação, desinibir-se.

"Eu estava pronto... eu queria alguma relação, nada sério, só mesmo para ter relações (sexuais), nada de sério."

Entrevistado 6 (39 anos, solteiro). Os seus amigos partilhavam consigo experiências que tinham através do Tinder. Ao terminar o relacionamento instalou a aplicação.

"Procuro acima de tudo sexo e em segundo lugar... ou seja... não procuro uma relação, pelo contrário, não procuro uma relação ou uma coisa séria. Então, pessoas fixes, descomplexadas e tranquilas que estejam à procura de one night stands ${ }^{3}$, hum... one night stands talvez não seja, mas à procura de partilhar momentos agradáveis para ambos, com sexo incluído."

Entre aqueles cuja principal motivação era encontrar alguém com quem ter sexo, as alterações na trajetória de vida estão relacionadas com turning points já identificados anteriormente: término de relação, estar sozinho, mudança

3 A expressão "one night stand" é traduzida como envolvimento de cariz sexual efémero que apenas ocorre numa ocasião. 
de residência e aspetos relacionados com o grupo de amigos, contextualizado pelo facto de não se quererem envolver com estes na medida em que poderia deteriorar a relação de amizade existente ao não terem objetivos comuns. O mesmo se verificou com amigos de amigos.

Eu não me vou envolver com o meu grupo do ginásio porque eu sei o que é que quero. Se as pessoas estiverem no mesmo registo que eu tranquilo, agora não vou arranjar um problema. [Entrevistado 3, 49 anos, divorciado]

Porém, com o evoluir das relações, o sexo, para os participantes, surge como algo consequente e natural. Apesar de referirem que essa não era a principal motivação para tal, poderia surgir como consequência do relacionamento com determinado(s) utilizador(es).

Entrevistado 4 (35 anos, solteiro). Explica quais as motivações que o levaram a usar a aplicação.

"De começar, de conhecer raparigas pelo menos e aumentar a minha rede de contactos e eventualmente envolver-me com as pessoas."

\section{CONSIDERAÇÕES FINAIS}

A análise temática dos 27 casos permitiu identificar um conjunto de motivações para o recurso ao Tinder enquadradas pela teoria dos usos e gratificações e onde se registaram motivações de ordem social, psicossocial e física entre as que se destacaram: socializar, ter um relacionamento e conhecer alguém com quem ter sexo. De salientar que as motivações dos utilizadores não são estanques, estáticas e unidimensionais. Variáveis como a fase da vida e as suas vivências, acontecimentos e a sua auto-perceção influenciaram o uso e contextualizaram as motivações. De forma dialética, o próprio uso da aplicação e seus resultados, mais ou menos gratificantes, produziram efeitos nos usos, como apontado pela teoria dos usos e gratificações.

A decisão de assumir um relacionamento, o que o utilizador procura no outro e o que deseja desse relacionamento vão variando ao longo do curso de vida (Sassler, 2010) tal como se registou ao longo dos testemunhos dos participantes de acordo com eventos vividos nas suas trajetórias de vida.

Porém, e independentemente da natureza das gratificações e da motivação, o uso da aplicação estava marcado nestes participantes do estudo por um conjunto de turning points ocorridos em diferentes domínios da vida, onde se incluíam aspetos como o término de um relacionamento, independentemente da sua duração e caráter de compromisso, alterações de ordem laboral 
ou escolar, e que podiam resultar na mudança de local de residência, mas também eventos ocorridos no grupo de amigos.

O grupo de amigos, como atores sociais tradicionais que podem facilitar novos contactos sociais, assume diversos papéis na relação dos participantes com o Tinder, tanto na contextualização das motivações como na identificação dos turning points. A homogeneidade social relativa ao grupo de amigos ou o desinteresse dos utilizadores pelo conjunto de pessoas que o compunham, eram razões para os participantes não recorrerem a esse grupo.

Por outro lado, a fundação de compromissos de caráter permanente ou duradouro que poderiam inclusive conduzir à parentalidade funcionava como fator de afastamento do grupo de pares pela ausência de objetivos comuns.

No polo oposto, e entre os utilizadores na fase dos jovens adultos, a aplicação surge como resposta/solução para o envolvimento e até relacionamentos de curto prazo podendo levar a um adiamento do matrimónio e a outras formas de compromisso íntimo e romântico (Arnett, 2004). Como aponta Nico (2016), as transformações lineares têm sido substituídas por trajetórias múltiplas.

Um ponto comum entre os participantes foi a perceção do Tinder enquanto uma ferramenta através da qual podiam conhecer novas pessoas, alargando a sua rede de contactos e muitas vezes permitindo sair dos círculos tradicionais mais offline. Não obstante, entre os pares, os amigos eram vistos como os grandes impulsionadores da utilização da aplicação ao darem-na a conhecer, por partilharem experiências de uso, legitimando e incentivando os entrevistados a utilizarem, remetendo tal uso para questões de pertença entre pares.

Na fase adulta, a aplicação apresenta-se também como uma solução para conhecer outras pessoas. O recurso à mesma é justificado, de forma geral, por aspetos similares ao dos jovens adultos: estagnação e homogeneidade do círculo de amigos, compromissos por parte destes, mas também a falta de vontade em assumir compromissos de caráter mais sério.

O término de um relacionamento, seja ele no formato separação ou divórcio, foi identificado pelos participantes como um turning point potenciador da instalação e uso da aplicação, independentemente da idade, género, orientação sexual, grau académico ou profissão dos entrevistados. Esta perceção ocorria para alguns participantes de forma imediata, mas para outros só após o decorrer de algum tempo, tal como previsto por Teruya e Hser (2010) e justificado por questões de ordem biográfica.

Mudanças de ordem laboral ou escolar (entrada na universidade ou realização de programas de intercâmbio), que implicavam a mudança de local de residência, logo reconfigurações espaciais e como tal das sociabilidades disponíveis offline, funcionaram também como turning point. Tais 
deslocações, dentro ou fora do país, poderiam ser temporárias, com um prazo estipulado, ou por tempo indeterminado. Nessas circunstâncias, o Tinder era apontado como um meio "natural" para conhecer outras pessoas e, ainda que os participantes já pudessem ter ouvido falar da aplicação, ou até ter amigos que a usavam, só com tais mudanças o uso da mesma se viu justificado e normalizado.

Ao longo da realização das entrevistas foi possível identificar turning points comuns entre os participantes para usarem o Tinder, porém a biografia individual de cada um, na qual a perceção dos acontecimentos tomou forma, foram fundamentais para contextualizar as motivações que levaram ao uso da aplicação.

\section{LIMITAÇÕES}

Focando a análise na orientação sexual, apesar da pouca variedade da amostra, não se registaram diferenças no conjunto de motivações identificadas. Estes dados vão ao encontro do que a literatura tem revelado (Van de Wiele e Tong, 2014) e que pode ser explicado pela natureza da aplicação ao não se tratar de uma aplicação exclusiva para homossexuais. Quando focados nos turning points, também não se registaram diferenças.

Para uma visão integral da utilização de aplicações de online dating e para uma compreensão geral de como as mesmas são integradas no conjunto de atividades diárias dos seus utilizadores, seria interessante explorar a familiaridade dos participantes com estas. Também seria importante abordar, do ponto de vista das experiências, os motivos que conduzem ao abandono da utilização da aplicação. ${ }^{4}$

4 Os autores agradecem às/aos utilizadoras/es do Tinder que participaram no estudo e às/aos revisoras/es anónimas/os do artigo pelas suas sugestões e comentários. Este trabalho foi financiado através de fundos do MCTES/FCT - Fundação para a Ciência e a Tecnologia, no âmbito da bolsa de doutoramento com a referência SFRH/BD/130648/2017. 


\section{REFERÊNCIAS BIBLIOGRÁFICAS}

abramova, O. et al. (2016), "Gender differences in online dating: what do we know so far? A systematic literature review". $49^{\text {th }}$ Hawaii International Conference on System Sciences.

ALbury, K. et al. (2017), "Data cultures of mobile dating and hook-up apps: Emerging issues for critical social science research". Big Data and Society, 1-11. DoI: 10.1177/2053951717 720950.

ANZANI, A., DI SARno, M., PRUnAS, A. (2018), "Using smartphone apps to find sexual partners: a review of the literature”. Sexologies, 27, pp. e61-e65. DoI:10.1016/j.sexol.2018.05.002.

APP ANNIE (2019), "Rank history Tinder". Disponível em www.appnie.com.

ARnETT, J. J. (2004), Emerging adulthood: The Winding Road from the Late Teens Through the Twenties, Nova Iorque, Oxford University Press.

blackwell, C., Birnholz, J., Аввотt, C. (2015), "Seeing and being seen: co-situation and impression formation using Grindr, a location-aware gay dating App”. New Media \& Society, 17(7), pp. 1-20. DOI: 10.1177/1461444814521595.

BraUn, V., CLARKe, V. (2006), "Using thematic analysis in psychology". Qualitative Research in Psychology, 3 (2), pp. 77-101. http://dx.doi.org/10.1191/1478088706qpo63oa.

Bryman, A. (2012), Social Research Methods, Nova Iorque, Oxford University Press.

Caetano, A. (2018), "O léxico das crises biográficas". Análise Social, LIII (1), 226, pp. 88-111. DOI: $10.31447 /$ asooo32573.2018226.04.

CASIMIRO, C. (2014), "Portuguese online dating: exploring gender differences in self-presentations". Revista Teknokultura, 11(1), pp. 117-141.

CHAN, L.S. (2017), "Who uses dating apps? Exploring the relationships among trust, sensationseeking, smartphone use, and the intent to use dating apps based on the Integrative Model". Computers in Human Behavior, 72, pp. 246-258.

COUCh, D., LiAmputtong, P., PITts, M. (2012), "What are the real and perceived risks and dangers of online dating? Perspectives from online daters". Health Risks in the Media, 9(3), pp. 697-714. DOI: 10.1080/13698575.2012.720964.

CRESWELL, J. W. (2013), Qualitative inquiry and research design: choosing among five approaches, Los Angeles, Sage Publications.

DAvid, G., CAMbre, C. (2016), "Screened intimacies: Tinder and the swipe logic". Social Media \& Society, 2(2), pp. 1-11. DOI:10.1177/2056305116641976.

DIAMOND, L.M. (2004), "Emerging perspectives on distinctions between romantic love and sexual desire". Current Directions Psychological Science, 13(3), pp. 116-119.

Dolberg, P., Ayalon, L. (2018), "Subjective meanings and identification with Middle Age". The International Journal of Aging and Human Development, 87(1), pp. 52-76. https://doi. org/10.1177/0091415017721932.

DuguaY, S. (2016), "Dressing up Tinderella: interrogating authenticity claims on the mobile dating app Tinder". Information, Communication and Society, 20(3), pp. 1-17. https://doi. org/10.1080/1369118X.2016.1168471.

ELLISON, N., HEINO, R., GIBBS, J. (2006), "Managing impressions online: self-presentation in the online dating environment". Journal of Computer-Mediated Communication, 11(2), pp. 415-441. https://doi.org/10.1111/j.1083-6101.2006.00020.x.

ERIKSON, E. (1963), Childhood and Society (2nd ed.), Nova Iorque, W. W. Norton \& Company. eurostat. (2019), Internet Usage. Disponível em https://ec.europa.eu/eurostat/web/productsdatasets/product?code=tinooo 28 . 
feijten, P., MUlder, C. (2010), "Gender, divorce and housing - a life course perspective". In D. Reuschke (eds.), Wohnen und Gender. vs Verlag für Sozialwissenschaften, pp. 175-193. FINKeL, E., el al. (2012), "Online dating: a critical analysis from the perspective of Psychological Science”. Psychological Science in the Public Interest, 13(1), pp. 3-66. https://doi. org/10.1177/1529100612436522.

Ganito, C. (2016), Women Speak. Gendering the Mobile Phone, Lisboa, Universidade Católica Editora.

GIBson, J. J. (1979), The Ecological Approach to Perception, Hillsdale, NJ, Lawrence Erlbaum Associates.

GIELE, J., ELDER JR, G.H. (1998), Methods of Life Course Research: Qualitative and Quantitative Approaches, Sage Publications.

GUdelunas, D. (2012), “There's an app for that: The uses and gratifications of online social networks for gay men". Sexuality and Culture, 16(4), pp. 347-365. DoI: 10.1007/s12119012-9127-4.

HART, M. (2015), "Youth intimacy on tumblr. A pilot study". Young, 23(3), pp. 193-208. https:// doi.org/10.1177/1103308815577878.

helson, R., soto, C. J., CATE, R.A. (2006), "From young adulthood through the middle ages". In D. K. Mroczek, T.D. Little, (eds.), Handbook of Personality Development, Mahwah, NJ: Erlbaum, pp. 337-352.

HJORTH, L. (2013), "The place of the emplaced mobile: a case study into gendered locative media practices". Mobile Media and Communication, 1(1), pp.110-115. https://doi. org/10.1177/2050157912459738.

hobbs, M., owen, S., Gerber, L. (2016), "Liquid love? Dating apps, sex, relationships and the digital transformation of intimacy". Journal of Sociology, 53(2), pp. 271-284. DoI: $10.1177 / 1440783316662718$.

Hutchison, E. (2011), "A life course perspective". In Dimensions of Human Behavior: the Changing Life Course, SAge Publications, pp. 9-49.

Katz, E., Blumler, J. G., GURevitch, M. (1973-1974), “Uses and gratifications research”. Public Opinion Quarterly, 37(4), pp. 509-523.http://dx.doi.org/10.1086/268109.

KEMP, S. (2018), Digital Report. Disponível em https://datareportal.com/reports/digital-2018-p ortugal (Consultado em 12-04-2019).

LAROSE, R., EASTIN, M.S. (2004), "A social cognitive theory of Internet uses and gratifications: towards a new model of media attendance". Journal of Broadcasting and Electronic Media, 48(3), pp. 358-377. DOI: 10.1207/s15506878jobem4803_2.

LAWson, H. M., LECK, K. (2006), “Dynamics of internet dating”. Social Science Computer Review, 24(2), pp. 189-208. DOI: 10.1177/0894439305283402.

Lefebvre, L. (2017). "Swiping me off my feet: Explicating relationship initiation on Tinder". Journal of Social and Personal Relationships, 35(9), pp. 1205-1229. https://doi.org/10.11 7 7/0265407517706419.

LICOPPE, C., RIVIÉRE, C. A., MOREL, J. (2016), "Grindr casual hook-ups as interactional achievements”. New Media \& Society, 18(11), pp. 2540-2558. https://doi.org/10.1177/146144 4815589702.

LO IACONO, V., sYMONDS, P., BRown, D.H.K. (2016), "Skype as a tool for qualitative research interviews”. Sociological Research Online, 21(2), pp.1-15. DoI: 10.5153/sro.39.52.

MACKeE, F. (2016), "Social media in gay London: Tinder as an alternative to hook-up apps". Social Media \& Society, 2(3), pp. 1-10. 
NESI, J., PRINSTEIN, M. J. (2015), "Using social media for social comparison and feedback-seeking: gender and popularity moderate associations with depressive symptoms". Journal of Abnormal Child Psychology, 43(8), pp. 1427-1438. DoI: 10.1007/s10802-015-00 20-0.

NICO, M. (2016), "Romantic turning points and patterns of leaving home: contributions from qualitative research in a southern European country". European Societies, 18(4), pp. 389-409 .

PAlmgreen, P., Wenner, L., Rosengren, K. (1985), "Uses and gratifications research: the past ten years". In K. Rosengren, L. Wenner, P. Palmgreen (eds.), Media Gratifications Research: Current Perspectives, Beverly Hills, CA, Sage, pp. 1-40.

PARK, N., KeE, K.F., VAlenzuela, S. (2009), "Being immersed in social networking environment: Facebook groups, uses and gratifications, and social outcomes". Cyberpsychology Behavior, 12(6), pp. 729-733. DOI: 10.1089/cpb.2009.0003.

PATRICK, M.E., MAGGS, J. L., ABAR, C. C. (2007), "Reasons to have sex, personal goals, and sexual behavior during the transition to college". Journal of Sex Research, 44 (3), pp. 240-249. DOI: $10.1080 / 00224490701443759$.

PULGAR, S. (2019), "Intimidad y tecnologías digitales: transformación de las relaciones interpersonales en el uso de Tinder en Chile". Revista Teknokultura, 16, pp. 91-108.

QUINN, K.A. (2012), Visible pathways: a life course perspective on Technology Use and Relationship Reconnection. Tese de Doutoramento, University of Illinois, Chigado.

RANZini, G., LUtz, C. (2017), "Love at first swipe? Explaining Tinder self-presentation and motives". Mobile Media and Communication, 5(1), pp. 80-101. https://doi.org/10.1177/20 50157916664559.

SPenCer, L., PAHL, R. E., (2006), Rethinking Friendship: Hidden Solidarities Today. Princeton, NJ, Princeton University Press.

RÖNKA, A., ORAVAlA, S., PULKKNEN, L. (2003), “Turning points in adults' lives: The effects of gender and the amount of choice". J Adult Dev, 10, pp. 203-215.

RUBIN, A. M. (1994), "Media uses and effects: A uses-and-gratifications perspective". In J. Bryant, D. Zillmann (eds.), LEA's communication series. Media effects: Advances in theory and research, Hillsdale, NJ, us: Lawrence Erlbaum Associates, Inc, pp. 417-436.

Ruggiero, T.E. (2000), "Uses and gratifications theory in the $21^{\text {st }}$ Century". Mass Communication and Society 3(1), pp. 3-37. https://doi.org/10.1207/S15327825MCSo301_02.

SAlmons, J.E. (2016), Doing Qualitative Research Online, Londres, Sage.

SASSLER, S. (2010), "Partnering across the life course: sex, relationships, and mate selection". J Marriage Fam, 72(3), pp. 557-575. DoI: 10.1111/j.1741-3737.2010.00718.x.

sснвоск, A. (2015), "Communicative affordances of mobile media: portability, availability, locatability, and multimediality”. International Journal of Communication, 9, 1229-1246.

SEPÚlVEDA, R., VIEIRA, J. (2019), “Representações da aplicação online dating Tinder na imprensa escrita portuguesa”. Estudos em Comunicação, 29, pp. 1-20.

SIlverstone, R., HIRsCH, E. (eds.) (1992), Consuming Technologies: Media and information in domestic spaces. Londres/Nova Iorque: Routledge.

STATista (2016), "Most popular ios dating apps worldwide as of July 2016, by downloads (in millions)". Disponível em www.statista.com/statistics/607160/top-ios-dating-apps-worldwide-downloads/ (consultado em 10-05-2019).

Statista (2019), “Online dating: Portugal”. Disponível em www.statista.com/outlook/372/147/ online-dating/portugal (consultado em 20-04-2019). 
Sumter, S., vandenbosch, L., Ligtenberg, L. (2016), "Love me Tinder: untangling emerging adults' motivations for using the dating application Tinder". Telematics and Informatics, 34(1), pp. 67-78. https://doi.org/10.1016/j.tele.2016.04.009.

teruya, C., HSER, Y. (2010), “Turning Points in the Life Course: Current Findings and Future Directions in Drug Use Research". Curr Drug Abuse Rev., 3(3), pp. 189-195.

TESTer, G. (2018), "And then AIDs came along: A life course turning point and sub cohorts of older gay men”. Journal of Gay \& Lesbian Social Services, 30(1), pp. 33-48. DOI: 10.1080/1053 8720.2017 .1408516 .

TIMMERMANS, E., COURTOIs, C. (2018), "From swiping to casual sex and/or committed relationships: Exploring the experiences of Tinder users." The Information Society, 34, pp. 59-70. DOI: $10.1080 / 01972243.2017 .1414093$.

timmermans, E., De Caluwé, E. (2017), "Development and validation of the Tinder motives Scale (TMS)", Computers in Human Behavior, 20, pp. 341-350. https://doi.org/10.1016/j.ch b.2017.01.028.

VAN DE WIELE, C., TONG, S. (2014), "Breaking boundaries: The uses and gratifications of Grindr", Presented at the UbiComp '14, Seattle, Washington.

VIEIRA, J., SEPÚLVEDA, R. (2017), "A autoapresentação dos utilizadores portugueses na plataforma de online dating Tinder". Observatorio. $\left(\mathrm{OBS}^{\star}\right)$, 11(3), pp. 153-185.

WARD, J. (2016), "What are you doing on Tinder? Impression management on a matchmaking mobile app". Information, Communication and Society, 20(11), pp. 1644-1659. https://doi. org/10.1080/1369118X.2016.1252412.

whitty, M. T., CARr, A.N. (2006), Cyberspace Romance: The Psychology of online Relationships, Nova Iorque, Palgrave Macmillan.

wood, D. et al. (2017), "Emerging adulthood as a critical stage in the life course". In N. Halfon et al. (eds.), Handbook of Life Course Health Development, Springer, Cham, pp. 123-143.

yeO, T., YUNG, T. (2018), "Mr Right Now": temporality of relationship formation on gay mobile dating apps". Mobile Media \& Communication, 6(1), pp. 3-18. https://doi.org/10.11 77/2050157917718601.

YURCHISIN, J., WATCHRAVESRINGKAN, K., MCCABE, D.B. (2005), "An exploration of identity recreation in the context of internet dating". Social Behavior Personality, 33, pp. 735-750. DOI: https://doi.org/10.2224/sbp.2005.33.8.735.

Recebido a 25-06-2019. Aceite para publicação a 04-03-2020.

SEPÚLVEDA, R., VIEIRA, J. (2020), “Motivações para o uso de aplicações de online dating no contexto português: a relevância dos turning points”. Análise Social, 235, LV (2.ํ), pp. 300-330.

Rita Sepúlveda » racfc@iscte-iul.pt » Centro de Investigação e Estudos de Sociologia, Instituto Universitário de Lisboa (ISCTE-IUL) » Av. das Forças Armadas - 1649-026 Lisboa, Portugal » https://orcid.org/ooooooo3-4348-5637.

Jorge Vieira » jorge_vieira@iscte-iul.pt » Centro de Investigação e Estudos de Sociologia, Instituto Universitário de Lisboa (iscte-iul) » Av. das Forças Armadas - 1649-026 Lisboa, Portugal » https://orcid. org/0000-0002-1130-3731. 